УДК 612

DOI: http://dx.doi.org/10.11603/mie.1996-1960.2017.3.8152

\title{
ПІДХІД ДО ЗАСТОСУВАННЯ ВІДКРИТИХ РЕСУРСІВ БІОСИГНАЛІВ PHYSIONЕТ ДЛЯ ПРОВЕДЕННЯ РОЗРАХУНКУ ПОКАЗНИКІВ ВАРІАБЕЛЬНОСТІ СЕРЦЕВОГО РИТМУ ЗА ДАНИМИ ЕКГ (ЧАСОВИЙ АНАЛІЗ) У НАВЧАННІ СТУДЕНТІВ МЕДИКІВ
}

\author{
Д. В. Вакуленко, С. Н. Вадзюк, А. В. Семенець, \\ А. С. Сверстюк, О. М. Кучвара, Н. О. Кравець, \\ Н. Я. Климук, В. В. Лесів ${ }^{1}$ \\ ДВНЗ «Тернопільський державний медичний університет \\ імені І. Я. Горбачевського МОЗ України» \\ ${ }^{1}$ Тернопільський національний технічний університет ім. І. Пулюя
}

\begin{abstract}
Описано методику навчання студентів в Тернопільському державному медичному університеті імені І. Я. Горбачевського (предмет медична інсорматика, тема «Біосигнали»). Пропонується використання відкритого ресурсу біосигналів PhysioNet для проведення розрахунку показників варіабельності серцевого ритму за даними запису електрокардіограми (часовий аналіз) за допомогою користувацьких фрункцій Microsoft Excel VBA.
\end{abstract}

Ключові слова: часовий аналіз, PhysioNet, варіабельність серцевого ритму, біосигнали, ЕКГ.

\section{AN APPROACH TO THE USE OF PHYSIONET OPEN SOURCE BIOSIGNALS FOR CALCULATING THE HEART RATE VARIABILITY OF ECG (TIME ANALYSIS) IN THE TRAINING OF MEDICAL STUDENTS}

D. V. Vakulenko, S. N. Vadzyuk, A. V. Semenets, A. S. Sverstyuk, O. M. Kuchvara, N. O. Kravets, N. Y. Klymuk, V. V. Lesiv ${ }^{1}$

SHEI "I. Ya. Gorbachevsky Ternopil state medical university of MH of Ukraine" 1. Pul'uj Ternopil National Technical University

The methodology of teaching students at the I. Ya. Gorbachevsky Ternopil state medical university (the subject is medical informatics, the topic is «Biosignals») is described. It is proposed to use PhysioNet's open resource for analyzing heart rate variability on ECG records (time analysis) using the Microsoft Excel VBA user features.

Key words: time analysis, PhysioNet, heart rate variability, biosignals, ECG. 


\title{
ПОДХОД К ПРИМЕНЕНИЮ ОТКРЫТЫХ РЕСУРСОВ БИОСИГНАЛОВ РНҮSIONЕТ ДЛЯ ПРОВЕДЕНИЯ РАСЧЕТА ПОКАЗАТЕЛЕЙ ВАРИАБЕЛЬНОСТИ СЕРДЕЧНОГО РИТМА ПО ДАННЫМ ЭКГ (ВРЕМЕННОЙ АНАЛИЗ) В ОБУЧЕНИИ СТУДЕНТОВ МЕДИКОВ
}

\author{
Д. В. Вакуленко, С. Н. Вадзюк, А. В. Семенец, \\ А. С. Сверстюк, А. Н. Кучвара, Н. О. Кравец, \\ Н. Я. Климук, В. В. Лесив ${ }^{1}$ \\ ГВУз «Тернопольский государственный медицинский университет \\ имени И. Я. Горбачевского МЗ Украины» \\ ${ }^{1}$ Тернопольский национальный технический университет им. И. Пулюя

\begin{abstract}
Описана методика обучения студентов в Тернопольском государственном медицинском университете имени И. Я. Горбачевского (предмет медицинская инсорматика, тема «Биосигналы»). Предлагается использование открытого ресурса биосигналов PhysioNet для проведения расчета показателей вариабельности сердечного ритма по данным записей электрокардиограммы (временной анализ) с помощью пользовательских функций Microsoft Excel VBA.
\end{abstract}

Ключевые слова: временной анализ, PhysioNet, вариабельность сердечного ритма, биосигналы, ЭКГ.

Вступ. Серцево-судинні захворювання в Україні становлять серйозну проблему. Вони, посідаючи перше місце у структурі поширеності, зумовлюють більше половини всіх випадків смерті та третину причин інвалідності населення України. Медикосоціальний тягар хвороб системи кровообігу полягає ще і в тому, що вони суттєво впливають на тривалість і якість життя населення, на показники втрат економічного потенціалу країни. Саме тому боротьба з хворобами системи кровообігу на сучасному етапі $є$ першочерговою проблемою сучасної медицини [1].

Перспективним напрямком подолання зазначеної проблеми є вдосконалення існуючих методик інструментальної діагностики стану серцево-судинної системи шляхом розробки нових діагностичних і прогностичних ознак на основі вибору адекватних методів математичного та комп’ютерного аналізу біосигналів [2-5]. Робота серця як біофізичної системи супроводжується генеруванням всередині організму, на поверхні та за його межами електричних, магнітних та механічних (акустичних) полів, що у своїй просторово-часовій структурі відображають функціональний стан серцево-судинної системи людини і дозволяють проводити її діагностику.

Безперервний контроль роботи серця протягом тривалого часу потрібен багатьом пацієнтам.

Стрімка інформатизація медицини створює виклик для освітніх медичних установ, що полягає в максимально глибокому знайомстві майбутніх медиків з принципами аналізу біосигналів, а саме електрокардіограм (ЕКГ). В даний час при деяких захворюваннях серця застосовують різні пристрої та методи для моніторингу ЕКГ.

В кардіологічній практиці знаходить все більше застосування комп’ютерний аналіз ЕКГ.

Мета дослідження: розробити методику на основі відкритої бази даних біосигналів https:// physionet.org (рис. 1) знайомства студентів зі структурою біосигналу та підходами для його аналізу; з форматами збереження біосигналів. Запропонувати підхід для знайомства студентів медиків з принципами аналізу ЕКГ, проведення розрахунку показників варіабельності серцевого ритму (ВСР) в часовій області. Розроблені підходи застосувати для навчальних та в майбутньому для науково-дослідницьких цілей.

Матеріали та методи дослідження. Пропонується застосовувати базу даних PhysioNet, створену для накопичення біомедичних досліджень для навчання студентів медиків. Інтернетпортал PhysioNet був створений під егідою трьох інститутів США - National Institute of Biomedical Imaging and Bioengineering, National Institute of General Medical Sciences, National Institutes of Health. PhysioBank — це великий і постійно оновлюваний архів добре охарактеризованих цифрових записів медико-фізіологічних сигналів, часових послідовностей і пов'язаних з ними даних, створений для біомедичних досліджень. На сьогодні PhysioBank включає в себе понад 60 колекцій біомедичних сигналів, отриманих як від здорових людей, так і від пацієнтів 3 різними діагнозами. 


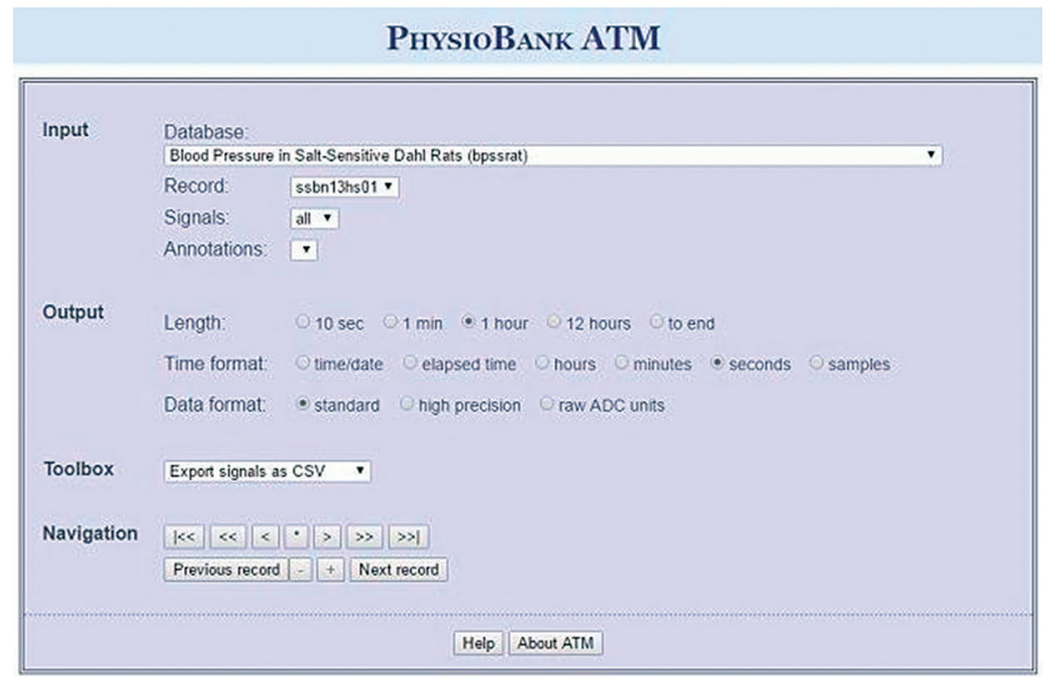

Рис. 1. Інтерфейс Physiobank ATM для вибору груп досліджень та налаштувань для завантаження біосигналів

Сигнали були записані у різних умовах, зокрема у випадках раптової смерті, за хронічної серцевої недостатності, епілепсії або протягом старіння. Бази даних PhysioNet містять відносно невелику кількість записів (від 10 до 1000). PhysioToolkit $\epsilon$ великою і стабільно зростаючою бібліотекою програмного забезпечення для обробки і аналізу сигналів, виявлення фізіологічно значущих подій, створення нових баз даних, моделювання фізіологічних та інших сигналів, кількісної оцінки і порівняння методів аналізу та аналізу нерівноважних і нестаціонарних процесів.

Студентам пропонується завантажити запис електрокардіосигналу за допомогою інтерфейсу Physiobank ATM (рис. 1) та імпортувати в середовище Microsoft Excel. На наступному етапі передбачено знайомство з часовим методом аналізу ЕКГ.

Спочатку студенти будують графік ЕКГ, за допомогою користувацьких функцій Microsoft Excel VBA проводять розрахунок RR-інтервалів завантаженої ЕКГ, візуально перевіряють вірність визначених екстремумів RR-інтервалів (рис. 2).

В лівій частині — вихідні дані RR-інтервалів, в правій верхній — побудована ЕКГ, а в нижній правій частині — графічне відображення Фур'є перетворення кардіосигналу.

До уточнених значень RR-інтервалів (рис. 3) застосовують методи часового аналізу ЕКГ для розрахунку показників ВСР за допомогою розроблених користувацьких функцій Microsoft Excel VBA. На наступному етапі студентам пропонується

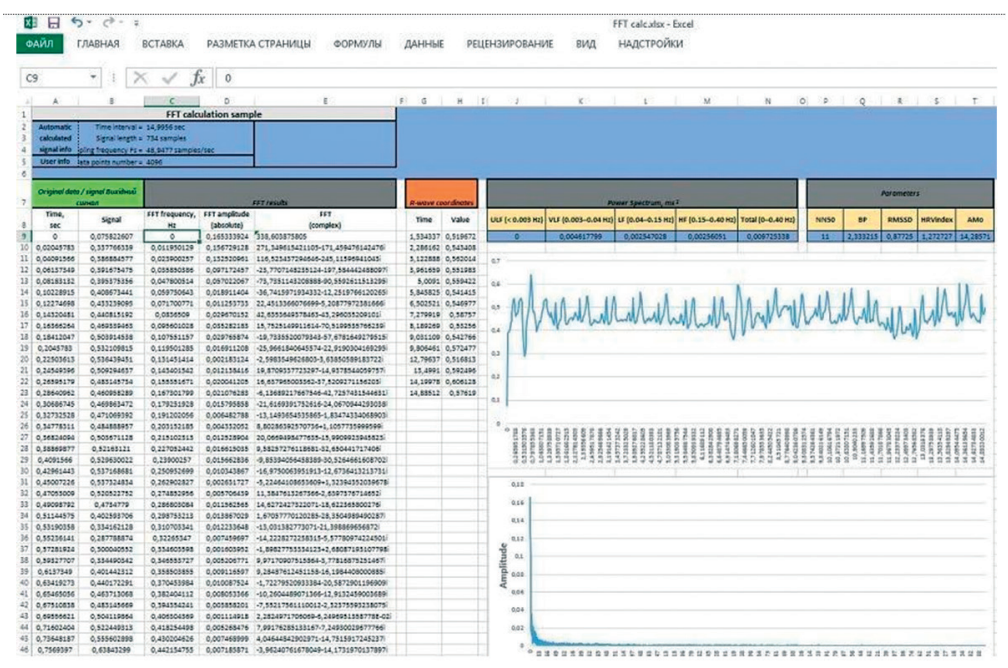

Рис. 2. Вигляд листа Microsoft Excel після проведених розрахунків 


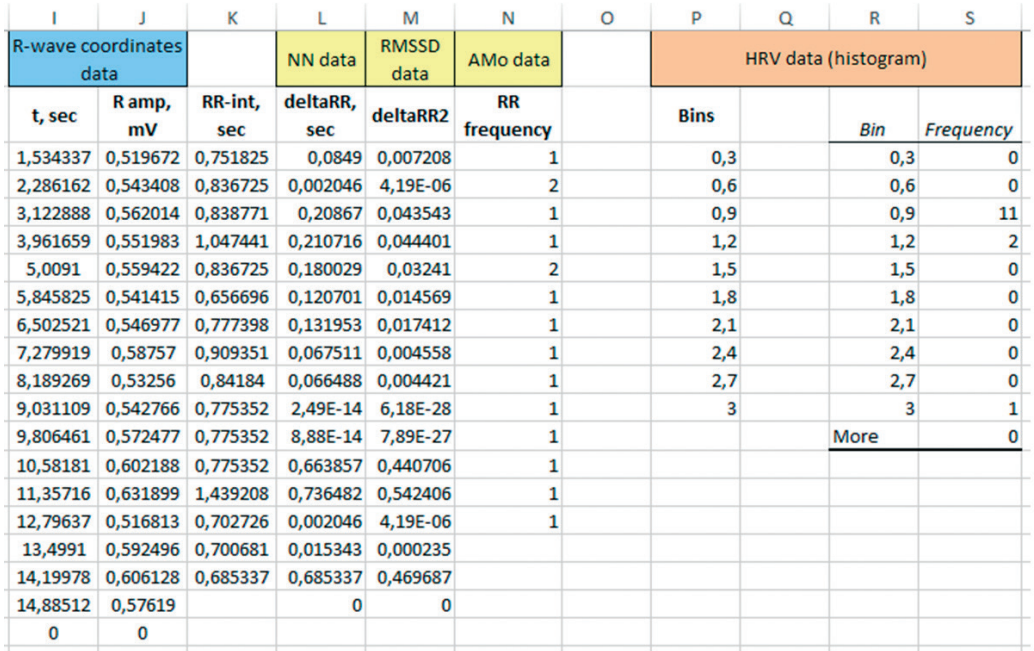

Рис. 3. Вигляд листа Microsoft Excel з даними для проведених розрахунку триангулярного індексу BCP (HRV index) (використано RR-int, sec. та значення HRV data (histogram) Frequency)

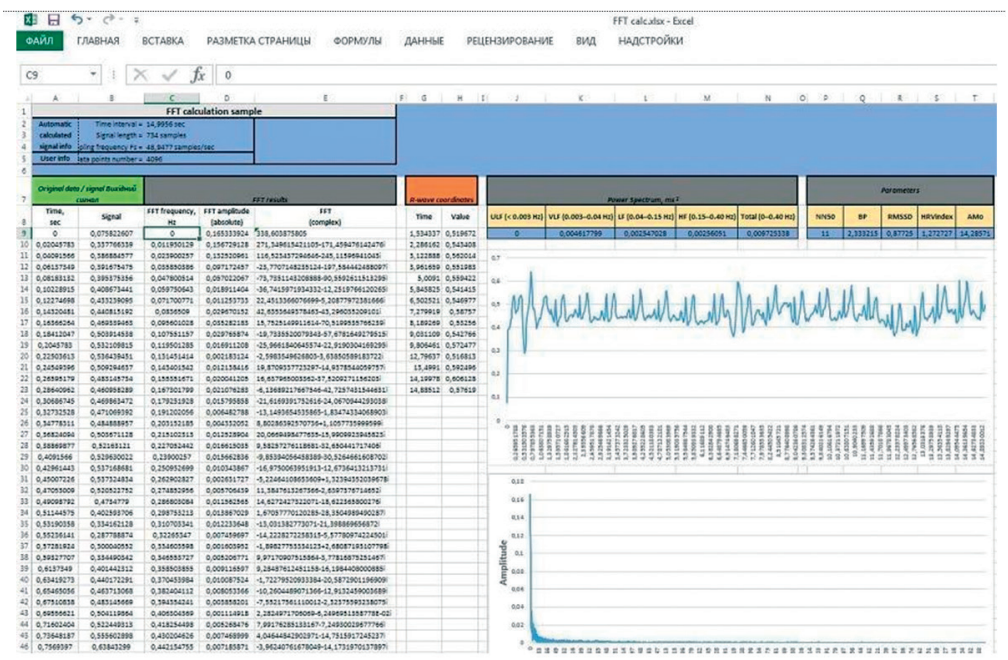

Рис. 4. Вигляд листа Microsoft Excel з формулою для підрахунку триангулярного індексу BCP (HRV index)

порівняти розраховані показники зі значеннями норми.

Приклад підрахунку одного із показників часового аналізу. Триангулярний індекс BCP (HRV index) обраховується за формулою:

\section{$=$ COUNT $($ DataCalc $! \mathrm{K}: \mathrm{K}) /$ \\ MAX (DataCalc!S:S)}

Висновки. Запропонована інформаційна технологія дозволяє студентам отримати досвід застосування відкритих баз біосигналів, розрахунку показників ВСР за даними ЕКГ на основі показників часового аналізу біосигналів при діагностиці серцево-судинної системи. Отримана інформація

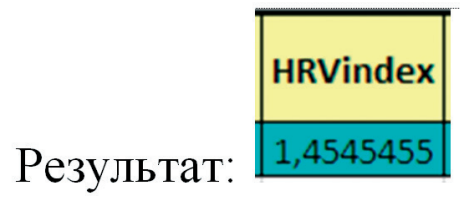

Рис. 5. Результат обрахунку триангулярного індексу BCP (HRV index)

допомагає оцінити стан гемодинамічних процесів, регуляції і управління станом серцево-судинної системи, активність та взаємодію різних ланок нервової системи, рівень функціонування міокардіально-гемодинамічного гомеостазу, тонус та реактивність периферійних судин. 


\section{Література.}

1. Коваленко В. М. Хвороби системи кровообігу в Україні: проблеми і резерви збереження здоров’я населення / В. М. Коваленко, А. П. Дорогой // Серце і судини. - 2003. - № 2. - С. 4-10.

2. Вакуленко Д. В. Інформаційна система морфологічного, часового, частотного та кореляційного аналізу артеріальних осцилограм у фізичній реабілітації : монографія / Д. В. Вакуленко. - Тернопіль : ТДМУ, 2015. - 212 c.

3. Лупенко С. А. Статистичний сумісний аналіз кардіосигналів на основі вектора циклічних ритмічно пов’язаних випадкових процесів / С. А. Лупенко, Я. В. Литвиненко, А. С. Сверстюк // Електроніка та системи управління — 2008. - Т. 18, № 4. — С. 22-29.

4. David A. How slow is the k-means method? / D. Arthur, S. Vassilvitskii // Proceedings of the twenty-second mannual symposium on computational geometry (SoCG) (Sedona, Arizona, USA, June 05-07, 2006). New York, USA : ACM Press, 2006. — P. 144.

5. Rodgers J. L. Thirteen ways to look at the correlation coefficient / J. L. Rodgers, W. A. Nicewander // The American Statistician. — 1988. — No. 42. — C. 59-66.

\section{References.}

1. Kovalenko, V. M. Dorogoi, A. P. (2003). Khvorobi sistemi krovoobigu v Ukraini: problemi i rezervi zberezhennya zdorov'ya naselennya [Diseases of the circulatory system in Ukraine: problems and reserves of public health maintaining]. Sertse i sudini (Heart and Vessels), 2, 4-10.

2. Vakulenko, D. V. (2015). Informatsiina sistema morfologichnogo, chasovogo, chastotnogo ta korelyatsiinogo analizu arterial'nikh ostsilogram $\mathrm{u}$ fizichnii reabilitatsii [Information system of morphological, temporal, frequency and correlation analysis of arterial oscillograms in physical rehabilitation]: monography. Ternopil’: TSMU.

3. Lupenko, S. A., Litvinenko, Ya. V., Sverstyuk, A. S. (2008). Statistichnii sumisnii analiz kardiosignaliv na osnovi vektora tsiklichnikh ritmichno pov'yazanikh vipadkovikh protsesiv [Statistical joint analysis of cardiosignals based on the vector of cyclic rhythmically coupled random processes]. Elektronika ta sistemi upravlinnya (Electronics and control systems), 18(4), 22-29.

4. Arthur, D., \& Vassilvitskii, S. (2006). How slow is the k-means method? In Proceedings of the twenty-second mannual symposium on Computational geometry SCG '06 (p. 144). New York, USA: ACM Press.

5. Rodgers, J.L., Nicewander, W. A. (1988). Thirteen ways to look at the correlation coefficient. The American Statistician, 42(1), 59. 